\title{
Crown Lengthening Revisited
}

\author{
Marianne Ong, ${ }^{*}$ Shih-Chang Tseng, ${ }^{\dagger}$ and Hom-Lay Wang ${ }^{\ddagger}$
}

Focused Clinical Question: What are the key considerations in selecting the best approach to crown lengthening?

Summary: Crown lengthening is a surgical procedure that involves manipulation of either soft tissue or both soft and hard tissue around a tooth or teeth for esthetic or restorative purposes. Esthetic crown lengthening is indicated in patients with excessive gingival display (known as a gummy smile) or gingival overgrowth, whereas restorative (or functional) crown lengthening aims to gain retention and resistance form of sound tooth structure above the alveolar crest level in cases of subgingival caries, subgingival restorative margins, or tooth fracture. Both aim to increase the amount of supragingival tooth structure for esthetic and/or restorative purposes.

Conclusions: In selecting the type of procedure for esthetic or restorative (or functional) crown lengthening, the key considerations include assessment of the width of keratinized gingiva and distance of the cementoenamel junction or finished restoration margin to alveolar bone around the tooth/teeth involved. This article reviews and presents a decision tree in the use of both types of procedures. In addition, the subtle differences between esthetic and restorative (or functional) crown lengthening are highlighted. Clin Adv Periodontics 2011;1:233-239.

Key Words: Crown lengthening, methods; decision trees; esthetics, dental; gingival hyperplasia, surgery; tooth crown, pathology; wound healing, physiology.

\section{Background}

Crown lengthening aims to increase the clinical crown length of a tooth or teeth for either esthetic or restorative purposes or a combination of both. The surgical procedure is designed to increase the extent of the supragingival tooth structure by apically positioning the gingival margin, removing supporting bone, or both. ${ }^{1}$ Factors taken into consideration include excessive gingival display (known as a gummy smile), altered passive eruption (in which the alveolar crest is $\leq 2 \mathrm{~mm}$ from the cemento-enamel junction

\footnotetext{
* Department of Restorative Dentistry, National Dental Centre, Singapore.

† Private practice, Taipei, Taiwan.

$\ddagger$ Department of Periodontics and Oral Medicine, University of Michigan School of Dentistry, Ann Arbor, MI.
}

Submitted May 2, 2011; accepted for publication June 7, 2011
[CEJ]), lack of tooth structure, or access for restorative purposes (requiring the removal of soft or hard tissue or a combination of both) and the adjacent periodontium of neighboring teeth. Indications for crown lengthening thus include teeth with subgingival caries or extensive caries that shortens the tooth, fractures, and short clinical crowns caused by incomplete exposure of the anatomic crowns.

The procedure is based on two principles: biologic width (BW) establishment and maintenance of adequate keratinized gingiva $(\mathrm{KG})$ around the tooth. The $\mathrm{BW}$ is defined as the dimension of soft tissue that is attached to the portion of the tooth coronal to the alveolar bone crest. ${ }^{2,3}$ Studies indicate that a minimum of $3 \mathrm{~mm}$ of space between restorative margins and alveolar bone would be adequate for periodontal health, allowing for $2 \mathrm{~mm}$ of BW space and $1 \mathrm{~mm}$ for sulcus depth. ${ }^{4,5}$ An adequate width of KG should be maintained around a tooth $(\geq 2 \mathrm{~mm})$ for gingival health whenever possible. ${ }^{6}$ This article presents guidelines for both types of crown lengthening, their indications and differences, and a decision tree in deciding when to use the procedures.

\section{Esthetic Crown Lengthening}

Crown lengthening for esthetic reasons aims to correct either a gummy smile or gingival overgrowth (Fig. 1). The periodontal status of the involved teeth is first assessed. In the presence of periodontal disease with an absence of gingival overgrowth, regular periodontal treatment will resolve the gingival inflammation and swelling with removal of local irritating factors. In cases in which tissues are inflamed with the presence of gingival overgrowth, a gingivectomy/gingivoplasty procedure may be indicated if the gingival overgrowth persists even after gingival inflammation has been reduced through initial periodontal therapy (e.g., in drug-induced gingival enlargements associated with cyclosporin and/or calcium channel blockers).

For a gummy smile with a healthy periodontium, the patient's facial proportion has to be assessed. A normal human face is divided into thirds, and 2 to $3 \mathrm{~mm}$ of tooth is usually shown with relaxed lips. ${ }^{7,8}$ If the facial proportion is normal, shallow probing depths $(<4 \mathrm{~mm})$ may indicate tooth malposition, and this can be corrected with orthodontic intrusion; deep probing depths ( $\geq 4 \mathrm{~mm}$ ) may indicate altered passive eruption (delayed apical migration of the gingival margin), and this can be corrected with crown-lengthening surgery. Vertical maxillary excess (VME) is a dentofacial condition associated with excessive vertical growth of the maxilla. Patients with VME may present with either a dental open or closed bite. An increased mandibular ramus height is associated with the latter. ${ }^{9}$ If the patient has VME with $\geq 8 \mathrm{~mm}$ of gingival display, 

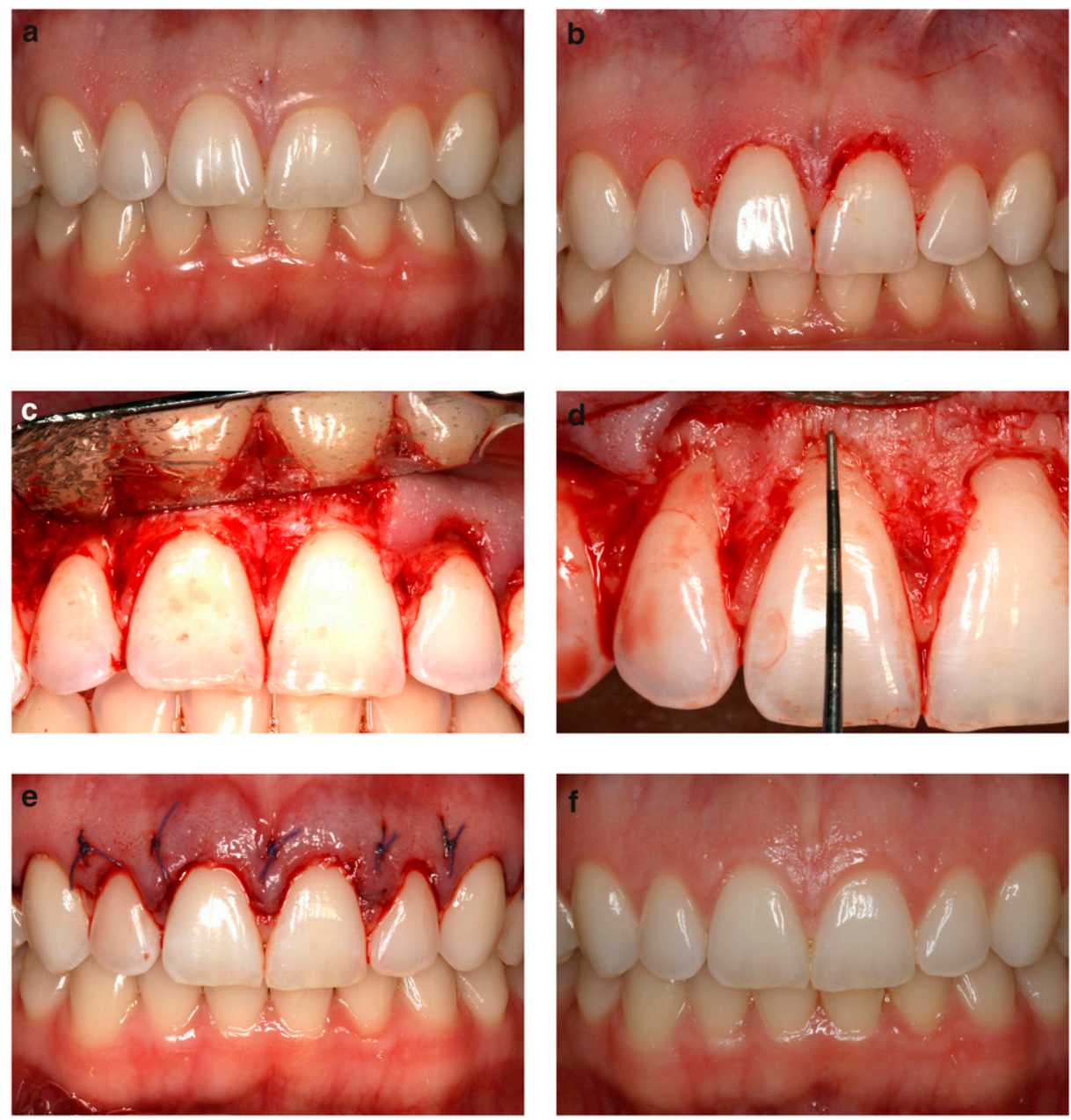

FIGURE 1 Esthetic crown lengthening. 1a Pretreatment. 1b Buccal incision made according to the esthetic smile line. 1c Full-thickness buccal flap reflected and interdental papillae left intact; note CEJ at alveolar bone crest (i.e., case Type IB: adequate $\mathrm{KG} \geq 2 \mathrm{~mm}$ and CEJ-bone $<2 \mathrm{~mm}$ ). 1d After osseous surgery, 2- to 3-mm BW established. 1e Sutures in place. 1f Seven months after treatment. (photos courtesy of Dr. Giorgio Pagni).

then orthognathic surgery would be the treatment of choice to address the problem. Garber and Salama ${ }^{10}$ presented three classifications for excessive gingival display and their proposed treatments. Degree I had 2 to $4 \mathrm{~mm}$ of gingival display, and treatment would be orthodontic intrusion alone, orthodontics and crown lengthening or crown lengthening followed by restorations. Degree II had 4 to $8 \mathrm{~mm}$ of gingival display, and treatment would be crown lengthening and restorations or orthognathic surgery depending on the crown/root ratio. Degree III had $\geq 8 \mathrm{~mm}$ of gingival display, and treatment would be orthognathic surgery with or without crown lengthening and restorative treatment. A decision tree for management of a gummy smile is illustrated in Figure 2.

The amount of KG present around teeth and the distance of the alveolar bone crest level in relation to the CEJ (CEJbone) is next determined clinically and radiographically. One of four possible treatment modalities may be considered as described by Coslet et al. ${ }^{11}$ For Type I cases with adequate $K G$ ( $\geq 2 \mathrm{~mm}$ ), if CEJ-bone is $\geq 2 \mathrm{~mm}$ (subgroup A), a gingivectomy/gingivoplasty procedure can be done. If CEJ-bone is $<2 \mathrm{~mm}$ or CEJ is at the same level as the alveolar bone crest (subgroup B), then a flap with osseous surgery is done. In Type II cases with inadequate $\mathrm{KG}(<2$ $\mathrm{mm}$ ), an apically positioned flap (APF) is indicated for subgroup A. For subgroup $\mathrm{B}$, an APF with osseous surgery is done. Figure 3 illustrates a decision tree for surgical crown lengthening.

The initial incision uses the CEJ as a reference point and follows the esthetic smile line, ensuring that $\geq 2 \mathrm{~mm}$ of $\mathrm{KG}$ remains on the buccal aspect of teeth. A surgical stent may be used to assist in placement of the buccal incisions according to the esthetic smile line. Only the buccal flap is raised as a full-thickness flap and a partialthickness flap raised over the interdental papillae area with the papillae left intact. No vertical releasing incisions are made, and a palatal flap is not raised. The CEJ-bone distance is assessed with a periodontal probe, and, when necessary, bone is removed only at the mid-buccal area, flushing it toward the mesio- and disto-buccal line angles to establish the BW; carbide, diamond round burs, and end-cutting burs are used. The buccal flap is next placed at the level of the CEJ or slightly above it. Horizontal positional sutures are used to secure the flap in place. A wound dressing is not necessary over the surgical site.

Based on wound healing principles and studies, ${ }^{12-16}$ tissue maturation is completed within 4 to 6 weeks if only a gingivectomy/gingivoplasty was done. If a buccal flap was raised and bone exposed, then 8 to 12 weeks would be required for tissue maturation and stabilization. If bone was removed, then $\geq 6$ months would be required for soft-tissue stabilization. ${ }^{17}$ A secondary surgery may be needed to refine the esthetic outcome of the smile line 6 to 12 weeks later.

\section{Restorative (or Functional) Crown Lengthening}

Crown lengthening for restorative reasons include increasing retention and to expose subgingival caries, fracture, or restorative margins by increasing the amount of sound tooth structure above the alveolar crest (Fig. 4).

Depending on the clinical and radiographic presentation, there are five modalities for this procedure. ${ }^{18-23}$ For a tooth with a probing depth $\geq 4 \mathrm{~mm}$ and in the presence of adequate $\mathrm{KG}$, a gingivectomy/gingivoplasty procedure is done. If there is inadequate $\mathrm{KG}$, then an APF is done. If there is a need to remove bone to establish BW, then an APF with osseous surgery is done. If there is a need to 


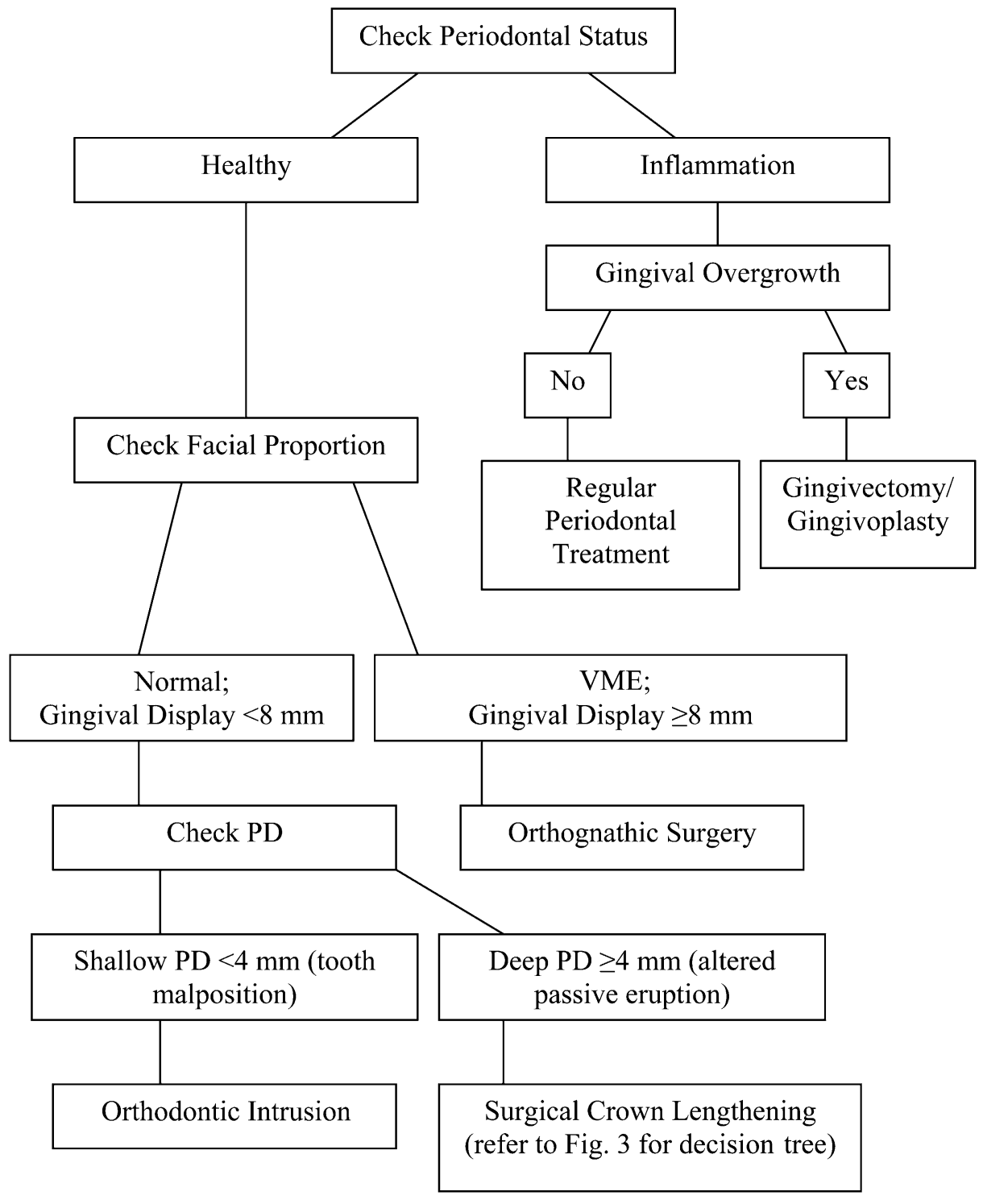

FIGURE 2 Decision tree for management of a gummy smile (excessive gingival display). PD = probing depth.

preserve adjacent structures and interdental papillae on neighboring teeth (e.g., fractured tooth in the anterior region), then orthodontic forced eruption of the tooth is done, which may require crown lengthening later. If the crown-lengthening procedure would create an undesirable crown/root ratio or induce more damage to the surrounding periodontium of adjacent teeth, then an extraction should be advised and a dental implant replacement can be considered at a later time.

There is a possibility of reviolating the BW during tooth preparation after the crown-lengthening surgery healing period, especially in areas of limited access, such as the distal line angles of a tooth. Immediate temporization crown lengthening has been described to alleviate this problem. It aims to create an adequate BW by establishing the finish margin of the restoration and fabricating a provisional restoration at the time of surgery. ${ }^{24}$

Before surgery is performed, an impression is taken of the dental arch with the tooth to be crown lengthened for a wax-up of the crown. A vacuform is prepared for the provisional restoration. Initial preparation of the tooth is done, and the prefabricated vacuform is used to make the provisional restoration. Incisions are made on the buccal and palatal/lingual aspects, following the APF concept, ensuring that $\geq 2 \mathrm{~mm}$ of $\mathrm{KG}$ remain on the buccal and lingual aspects of the flaps for mandibular teeth. For maxillary teeth, the palatal flap incision is one half to two thirds of the palatal probing depth (an enhanced scalloped incision) because the flap cannot be apically positioned as a result of the immobility of the palatal tissue. Vertical releasing incisions are usually placed to assist in apically positioning the flap on the buccal aspect. Buccal and palatal/ lingual flaps are raised, and the finish margin of the restoration is established to the best of the operator's ability during the surgery. The provisional restoration is then relined. With the finished restoration margin (FRM) as a reference, the BW is established around the tooth by removing bone to $\geq 3 \mathrm{~mm}$ below the FRM. If a ferrule effect is required for endodontically treated teeth that need to be restored with a cast post and core, then 4 to 5 $\mathrm{mm}$ of clearance is needed from the finish margin to the alveolar bone. ${ }^{25,26}$ Osseous surgery is done with carbide, diamond round burs, and end-cutting burs circumferentially around the tooth.

In some instances, an alternative to osseous resection alone would be to reshape the existing tooth/root surface in combination with conservative removal of supporting alveolar bone to create the BW. Reshaping of the external surface or periphery of the tooth and the core buildup restoration aims to advance the restoration coronally and minimize the amount of ostectomy required to create the BW. ${ }^{27}$

The provisional restoration is cemented on to the tooth. The buccal and palatal/lingual flaps are placed at the alveolar bone crest and sutured. A vertical mattress suture is used to close the flaps if crown lengthening involved a single tooth. If crown lengthening involved multiple teeth, a continuous sling suture may be used instead. A periodontal dressing is often used to protect the surgical site and to assist in positioning the flap apically.

Because bone removal is done during the procedure, a minimum of 6 months is needed for complete tissue maturation and stabilization before cementation of the final restoration. ${ }^{17}$ The development of black triangles between teeth usually occurs if the post-surgery distance 


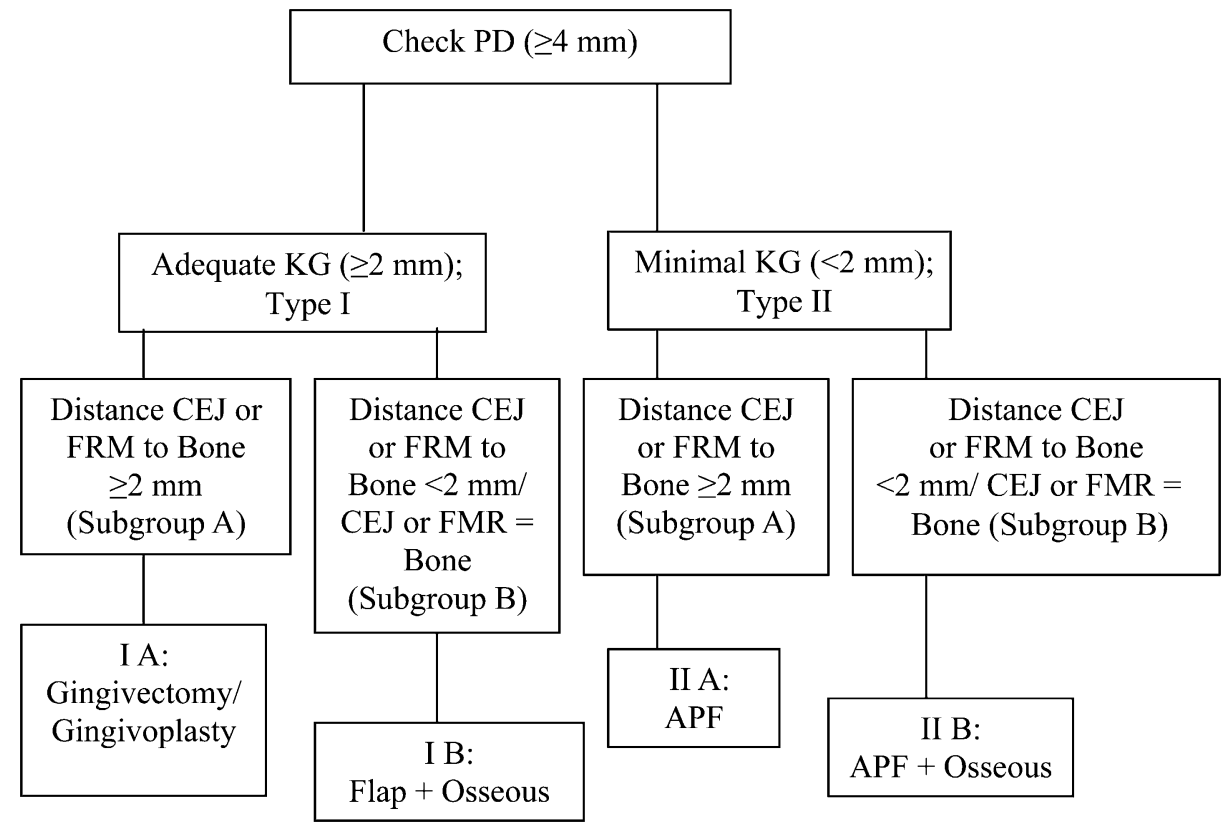

FIGURE 3 Decision tree for surgical crown lengthening: esthetic and restorative (or functional). PD = probing depth.

between the contact area and the interdental alveolar crest is $>5 \mathrm{~mm} .{ }^{28}$ Thus, as a result of establishing the $\mathrm{BW}$ around the tooth, the interdental spaces become larger and the final restoration usually ends up with a square-looking crown and long contact points to close up these spaces.

\section{Discussion}

Various factors need to be taken into consideration for surgical crown-lengthening indications of a tooth. These include the strategic value of the tooth, apical extent of fracture or caries, level of the alveolar crest, and crown/ root ratio before and after surgery. With the advent of implant dentistry, surgical crown lengthening may be contraindicated in cases with an unfavorable crown/root ratio, preexisting tooth mobility, possibility of compromising the support of the adjacent dentition, and in esthetic areas. 22,23

The decision-making process in managing a gummy smile and techniques for crown lengthening under various clinical scenarios are illustrated in Figures 2 and 3. The differences between esthetic and restorative (or functional) crown lengthening are summarized in Table 1.
Both procedures aim to establish the $\mathrm{BW}$ around the tooth and to maintain an adequate width of $\mathrm{KG}$ for different purposes: one to create an esthetic smile line and the other to recreate the BW to maintain periodontal health around a tooth that needs to be restored. The reference lines with respect to making incisions and performing osseous surgery are different: the CEJ for esthetic crown lengthening and the FRM for restorative crown lengthening. The final outcomes also differ. With esthetic crown lengthening, often the clinician is exposing more of the anatomic crown height of the natural teeth, with an esthetic smile resulting. In restorative crown lengthening, the teeth require restorations for a variety of reasons and frequently esthetics are achieved with the final restorations having square-looking crowns and long contact points.

\section{Conclusions}

This article reviews esthetic and restorative (or functional) crown-lengthening procedures and highlights their indications and differences. In addition, decision trees are presented to aid the clinician in the decision-making process of when these procedures should be used.

\section{Acknowledgments}

This study was partially supported by the University of Michigan Periodontal Graduate Student Research Fund. The authors thank Dr. Giorgio Pagni (private practice, Florence, Italy, and former resident, Graduate Periodontics at the University of Michigan, Ann Arbor, MI) for providing Figure 1. The authors report no conflicts of interest related to this study.

CORRESPONDENCE:

Dr. Hom-Lay Wang, Department of Periodontics and Oral Medicine, University of Michigan School of Dentistry, 1011 N. University Ave., Ann Arbor, Ml 48109-1078. E-mail: homlay@umich.edu. 

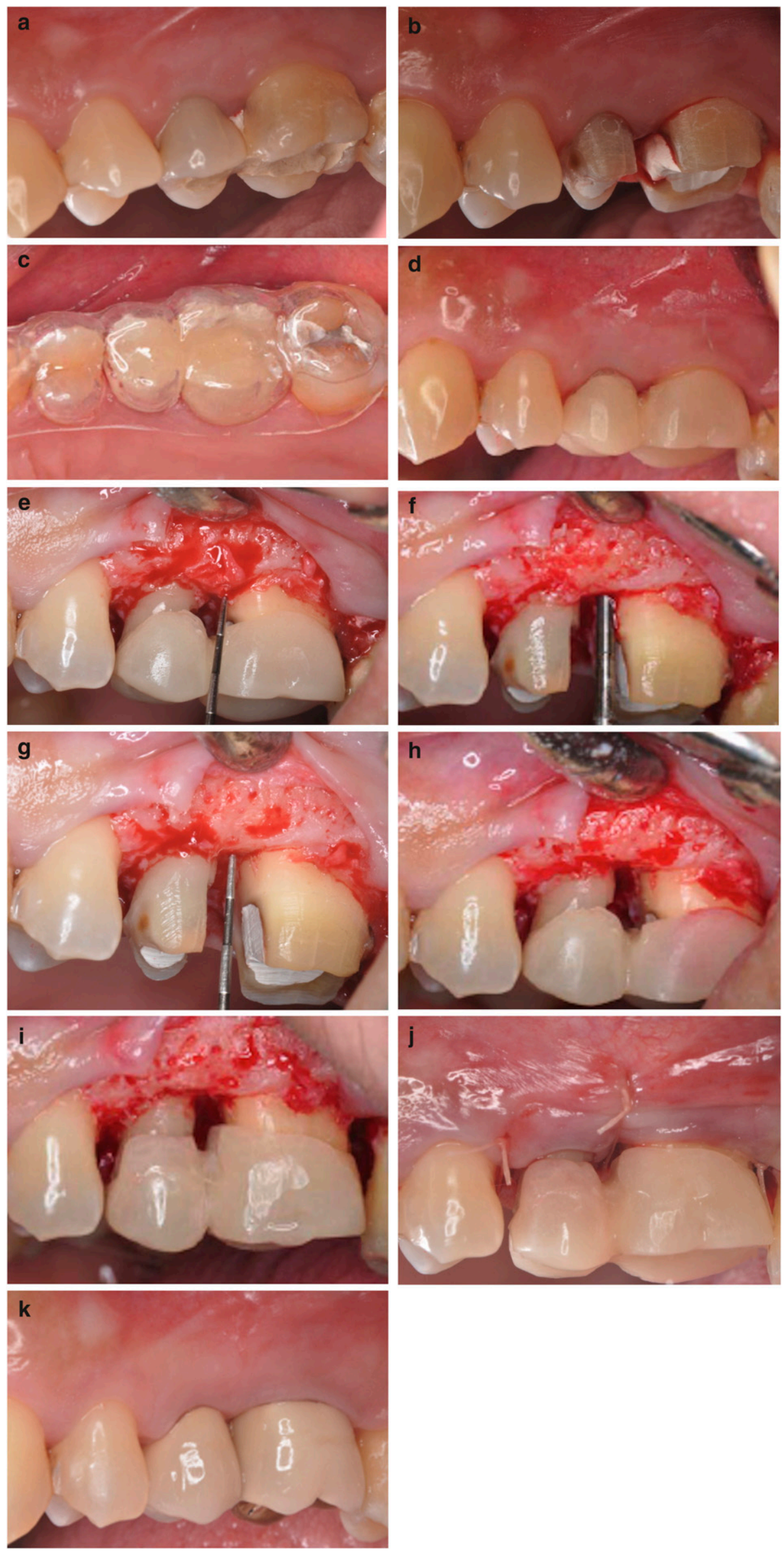

FIGURE 4 Restorative (or functional) crown lengthening. 4a Pretreatment. 4b Initial crown preparations done. 4c Vacuform placed to make provisional restorations. 4d Provisional restorations fabricated. 4e After flap reflection and softtissue debridement, finish margin of restorations established and existing distance to alveolar bone determined. 4f End-cutting bur used for osseous surgery to remove bone to $\geq 3 \mathrm{~mm}$ below finish margin of restorations. $\mathbf{4 g}$ BW established after surgery. 4h Provisional restorations replaced. 4i Provisional restorations relined and subsequently adjusted and trimmed. $4 \mathrm{j}$ Sutures in place and provisional restorations cemented. 4k Six months after treatment with crown placement. 
TABLE 1 Comparison Between Esthetic and Restorative (or Functional) Crown-Lengthening Surgery

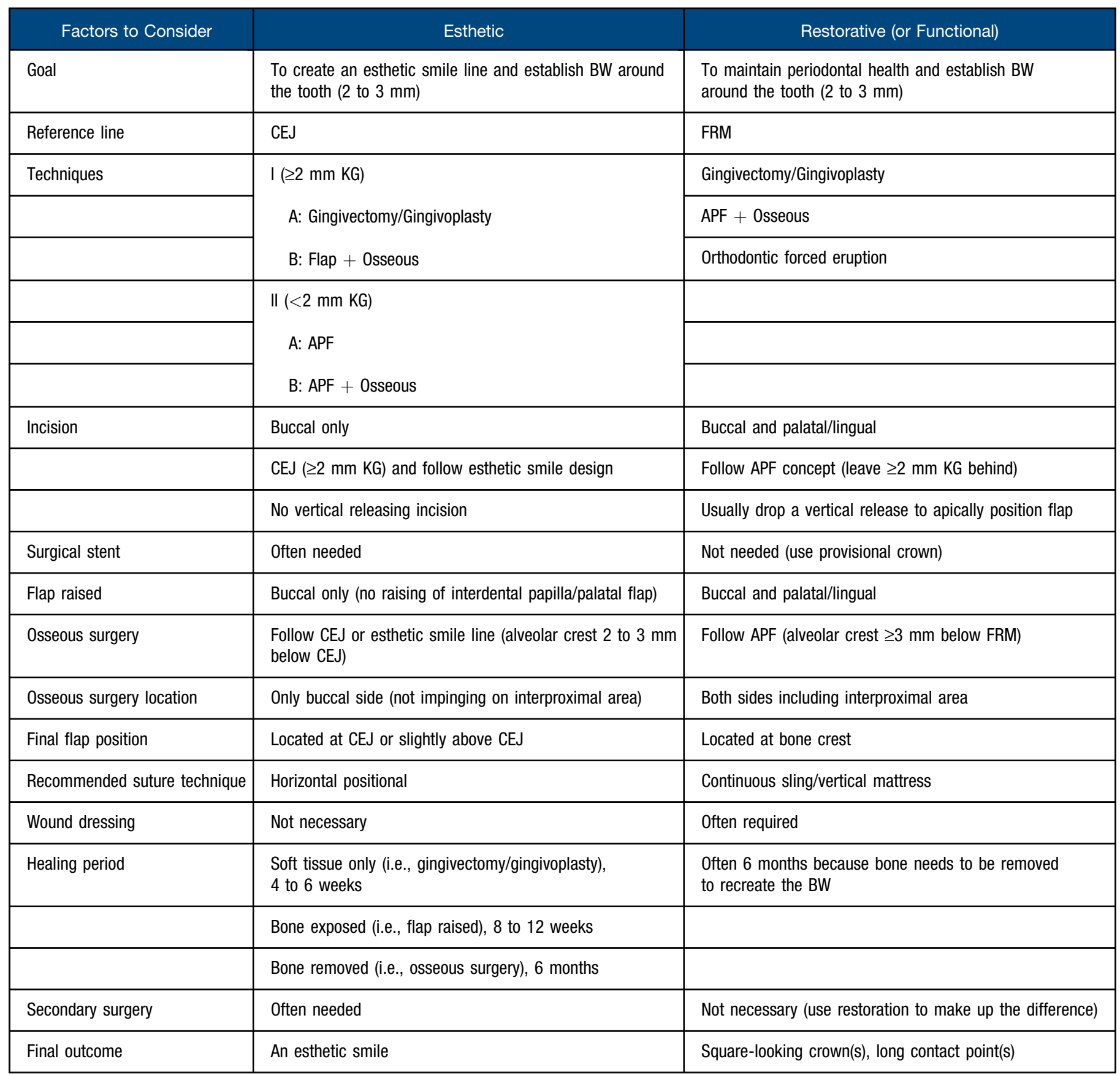




\section{References}

1. American Academy of Periodontology. Glossary of Periodontal Terms, 4th ed. Chicago: American Academy of Periodontology; 2001:11.

2. Gargiulo AW, Wentz FM, Orban B. Dimensions and relations of the dentogingival junction in humans. J Periodontol 1961;32:261-267.

3. Vacek JS, Gher ME, Assad DA, Richardson AC, Giambarresi LI. The dimensions of the human dentogingival junction. Int $J$ Periodontics Restorative Dent 1994;14:154-165.

4. Nevins M, Skurow HM. The intracrevicular restorative margin, the biologic width, and the maintenance of the gingival margin. Int J Periodontics Restorative Dent 1984;4(3):30-49.

5. Block PL. Restorative margins and periodontal health: A new look at an old perspective. J Prosthet Dent 1987;57:683-689.

6. Lang NP, Löe H. The relationship between the width of keratinized gingiva and gingival health. J Periodontol 1972;43:623-627.

7. Levin EI. Dental esthetics and the golden proportion. J Prosthet Dent 1978;40:244-252.

8. Mack MR. Perspective of facial esthetics in dental treatment planning. J Prosthet Dent 1996;75:169-176.

9. Schendel SA, Eisenfeld J, Bell WH, Epker BN, Mishelevich DJ. The long face syndrome: Vertical maxillary excess. Am J Orthod 1976;70:398-408.

10. Garber DA, Salama MA. The aesthetic smile: Diagnosis and treatment. Periodontol 2000 1996;11:18-28.

11. Coslet JG, Vanarsdall R, Weisgold A. Diagnosis and classification of delayed passive eruption of the dentogingival junction in the adult. Alpha Omegan 1977;70:24-28.

12. Engler WO, Ramfjord SP, Hiniker JJ. Healing following simple gingivectomy. A tritiated thymidine radioautographic study. I. Epithelialization. J Periodontol 1966;37:298-308.

13. Ramfjord SP, Engler WO, Hiniker JJ. A radioautographic study of healing following simple gingivectomy. II. The connective tissue. J Periodontol 1966; 37:179-189.

14. Wagenberg BD, Eskow RN, Langer B. Exposing adequate tooth structure for restorative dentistry. Int I Periodontics Restorative Dent 1989;9:322-331.
15. Brägger U, Lauchenauer D, Lang NP. Surgical lengthening of the clinical crown. J Clin Periodontol 1992;19:58-63.

16. de Waal H, Castellucci G. The importance of restorative margin placement to the biologic width and periodontal health. Part II. Int J Periodontics Restorative Dent 1994;14:70-83.

17. Deas DE, Moritz AJ, McDonnell HT, Powell CA, Mealey BL. Osseous surgery for crown lengthening: A 6-month clinical study. J Periodontol 2004;75:1288-1294.

18. Allen EP. Surgical crown lengthening for function and esthetics. Dent Clin North Am 1993;37:163-179.

19. Nabers CL. Repositioning the attached gingiva. J Periodontol 1954;25: 38-39.

20. Ariaudo A, Tyrrell HA. Repositioning and increasing the zone of attached gingiva. J Periodontol 1957;28:106-110.

21. Friedman N. Periodontal osseous surgery: Osteoplasty and ostectomy. J Periodontol 1955;26:257-269.

22. Lundgren D, Rylander H, Laurell L. To save or to extract, that is the question. Natural teeth or dental implants in periodontitis-susceptible patients: Clinical decision-making and treatment strategies exemplified with patient case presentations. Periodontol 2000 2008;47:27-50.

23. Avila G, Galindo-Moreno P, Soehren S, Misch CE, Morelli T, Wang HL. A novel decision-making process for tooth retention or extraction. J Periodontol 2009;80:476-491.

24. Tseng SC, Fu JH, Wang HL. Immediate temporization crown lengthening. Compend Contin Educ Dent 2011;32:38-43.

25. Sorensen JA, Engelman MJ. Ferrule design and fracture resistance of endodontically treated teeth. J Prosthet Dent 1990;63:529-536.

26. Libman WJ, Nicholls JI. Load fatigue of teeth restored with cast posts and cores and complete crowns. Int J Prosthodont 1995;8:155-161.

27. Melker DJ, Richardson CR. Root reshaping: An integral component of periodontal surgery. Int J Periodontics Restorative Dent 2001;21:296304.

28. Tarnow DP, Magner AW, Fletcher P. The effect of the distance from the contact point to the crest of bone on the presence or absence of the interproximal dental papilla. I Periodontol 1992;63:995-996. 